\title{
Sentir el cuerpo: performance, tortura y masoquismo en el entorno de los nuevos comportamientos
}

\section{Feeling the Body: Performance, Torture and Masochism in Spanish Conceptualisms}

\author{
JuAn Albarrán-Diego \\ Duke University. Madrid \\ albarrandiego@yahoo.es
}

Recibido: 30 de abril de 2012

Aprobado: 18 de abril de 2012

\begin{abstract}
Resumen
Este artículo explora las relaciones entre la violencia que el Estado franquista ejercía sobre los cuerpos disidentes - sobre cualquiera que supusiese una amenaza para el mantenimiento del Régimen-y algunas estrategias performativas, más o menos próximas a las prácticas englobadas bajo el apelativo "nuevos comportamientos", vinculadas a su vez con un particular masoquismo, con una voluntad de potenciar aspectos táctiles - a través del dolor autoinflingido- y con un impulso de prospección fenomenológica de la realidad. Partiendo de los estudios de Kathy O’Dell y Sophie Delpeux, este texto pretende arrojar una nueva lectura política de ciertos trabajos performativos poniendo en valor el papel del medio fotográfico en su difusión y recepción e inscribiéndolos en el complejo proceso de transición hacia la democracia.
\end{abstract}

Palabras clave: arte conceptual, performance, tortura, transición.

Albarrán-Diego, J. (2013) Sentir el cuerpo: performance, tortura y masoquismo en el entorno de los nuevos comportamientos. Arte, Individuo y Sociedad, 25(2), 303-317

\begin{abstract}
This paper analyzes the relationship between the violence exercised by the Franco governement over the dissident bodies - on anyone who would present a threat to the maintenance of the dictatorship - , and some performative strategies close to the practices included under the label "nuevos comportamientos". These conceptual works were related with a kind of masochism, with a desire to promote tactile aspects - through self-inflicted pain - and with a phenomenological exploration of reality. Following the studies of Kathy O'Dell and Sophie Delpeux, this text aims to provide new political readings of several performances by highlighting the role of the photographic medium in their reception and contextualizing these works in the very complex political Spanish transition.
\end{abstract}

Key Words:conceptual art, performance, torture, transition.

Albarrán-Diego, J. (2013) Feeling the Body: Performance, Torture and Masochism in Spanish Conceptualisms. Arte, Individuo y Sociedad, 25(2), 303-317

Sumario: 1 . El arte ante la violencia política. 2. Performance y nuevos comportamientos. 3. Cuerpos en tránsito. Referencias. 


\section{El arte ante la violencia política}

Como es sabido, el uso de los espacios públicos estaba fuertemente regulado en la España franquista. Pero el Gobierno y sus aparatos de represión no sólo vigilaban los ámbitos de lo común. El poder también controlaba el espacio de lo privado: la privacidad de los individuos - su domicilio, su intimidad, su propio cuerpo- podía ser allanada en cualquier momento en busca de información o, simplemente, como un medio para intimidar y reprimir. Durante el último franquismo y la transición, el cuerpo - en especial, el cuerpo que disiente-, como último reducto de la intimidad y la identidad del individuo, estará siempre amenazado por la violencia política y la tortura. Ante esa pesada realidad, algunos artistas tratarán de exorzizar la violencia convirtiéndose en víctimas de sus propias torturas, como en un acto agónico y desesperado a través del cual conectar con un cuerpo social cansado y dolorido.

Ya durante la Guerra Civil, el Bando Nacional, vencedor de la contienda, va a hacer un uso constante de la tortura - a través de las Comisiones de Depuración, antecedente directo de la Brigada Político Social - como un medio para conseguir información, pero, sobre todo, como un fin en sí mismo, como una estrategia muy eficaz para aterrorizar a la población, humillar al "enemigo" y destruir el tejido disidente. La tortura es la negación del otro - físico y político-, su anulación (Savater y Martínez-Fresneda, 1982; Peters, 1987). Tiene como principales objetivos manipular las emociones del detenido, desestabilizarlo, hacerle perder la consciencia, desideologizarlo, aterrorizarle, reducir su resistencia hasta obligarle a facilitar información, generar en su interior una sensación de culpa que le lleve a autoinculparse, $\mathrm{o}$, en caso de no querer o no poder hablar, la tortura puede provocarle la muerte. Los testimonios de detenidos torturados coinciden en estos mismos aspectos (Batista, 1995; Gallardo, 2003 y 2006; Gómez Roda, 2005; Moreno, 1999): palizas, humillaciones y amenazas que dejan secuelas físicas y psicológicas de por vida. Sólo un control absoluto de la información podía permitir a un ejército —o a un régimen militar como el franquista, con un militar al frente del Estado y una jurisdicción militar vigente hasta 1964 (Águila, 2001; Vidal i Marsal, 2006) - controlar los movimientos de una militancia dispersa. La oposición al franquismo fue creciendo con el transcurso de los años. La disidencia se hacía más visible y, en consecuencia, la tortura continuó siendo una práctica habitual en las comisarías después, incluso, de la muerte del dictador. Como dato revelador, la plantilla del TOP (Tribunal de Orden Público) fue doblada en 1972 y, de sus 22.600 expedientes, el $60 \%$ corresponden a los tres últimos años de actividad de este tribunal -1974-1976- (Águila, 2001).

Dentro de esa creciente visibilidad de la oposición antifranquista, las prácticas artísticas desempeñaron un papel significativo. De hecho, desde las poéticas geométrico-constructivistas delEquipo 57 hasta ese cajón de sastre que es el conceptual español, continúa siendo absolutamente necesario replantear una historia política del arte en el Estado español (Albarrán, 2010). Y ello pese a las dificultades existentes para concretar dónde está el momento político del arte, dónde reside su capacidad para incidir en la realidad social. ¿En su potencial utópico, en la tematización de lo político, en la visibilización de actitudes resistentes, en la capacidad para generar comunidad, en una reestructuración de la economía de lo sensible que reactive la visión crítica del espectador? 
Con respecto a la violencia política y la toma de posición de artistas e intelectuales en general a lo largo de la dictadura, los modos de abordar el problema y hacer público el desacuerdo van a ser de lo más diverso. Ya en 1963 —el mismo año en que se crea el TOP_, 102 intelectuales españoles, encabezados por Vicente Aleixandre, Laín Entralgo, Valentín Andrés Álvarez y José Luis Aranguren, remiten un documento a Fraga Iribarne, Ministro de Información y Turismo, en el que protestan contra las torturas sufridas por los mineros en huelga de la localidad asturiana de Sama de Langreo. Entre los firmantes figuran artistas como Antonio Saura, Ángel Crespo, Pedro Serrano, Manolo Millares y Lucio Muñoz (Núñez, 2005, págs. 97-98). La violencia política era una preocupación constante para los intelectuales españoles además de un problema criticable desde el respeto a los valores católicos y los derechos humanos. La tortura - los malos tratos, la violencia generalizada - fue denunciada a través de diversos escritos y también fue tematizada en momentos diferentes, desde distintos lenguajes, de una manera más o menos explícita. Sin duda, es en el ámbito de los nuevos comportamientos donde encontramos obras que, de una manera más consciente y tal vez menos obvia, abordan cuestiones relacionadas con la violencia política a través de trabajos corporales y performativos en los que, como veremos, la fotografía desempeña un papel fundamental.

En este punto, resulta pertinente recuperar las teorías de Kathy O'Dell, profesora de la Universidad de Maryland y una de las autoras más interesantes en el campo de la teoría de la performance. Para O'Dell, durante los setenta, en un panorama político marcado por las protestas contra la guerra de Vietnam, al desvelarse con ayuda de la fotografía (Sontag, 1981, págs. 27-28) - las atrocidades que el ejército norteamericano cometía sobre la población civil, se produce un cambio en la mentalidad de los norteamericanos - y del occidental medio, por extensión-, que pierden la fe en los acuerdos políticos establecidos entre la ciudadanía y sus representantes al frente de los poderes estatales. Se descubre la enorme distancia existente entre los hechos y la representación de los mismos que proyectan los poderes políticos y mediáticos (O’Dell, 1998, pág. 11). Algo que desencadenaría protestas antibelicistas y un movimiento generalizado de activación política y lucha por los derechos civiles. En ese contexto, el masoquismo - entendido aquí como un castigo físico autoinflingido, al margen de sus connotaciones sexuales-, se convierte en una estrategia relativamente extendida entre los artistas que trabajan en el campo de la performance. O'Dell analiza desde un punto de vista psicoanalítico, tomando como referencia los escritos de Jacques Lacan y Didier Anzieu, los trabajos de Vito Acconci (Figura 1), Chris Burden, Marina Abramovic/Ulay y Gina Pane, para lo cual se centra en las causas que les llevan a convertirse en víctimas de sus propias "torturas" acudiendo, claro está, a un concepto expandido de tortura y no estrictamente a la tortura judicial一:

"Los performers masoquistas de los setenta se autoinflingían dolor para señalar los problemas de dos instituciones sociales interconectadas: la ley y la familia. Más especificamente, estos artistas concentraron su atención en el mecanismo en el cual se basaban estas instituciones: el contrato. En parte porque el masoquismo siempre depende de un contrato entre partes, se convierte en una clave metafórica a través de la cual estos artistas podian abordar las inestables cuestiones socio-politicas que afectaban a la vida cotidiana de los individuos a principios de los setenta.” (O’Dell, 1998, pág. 12). 

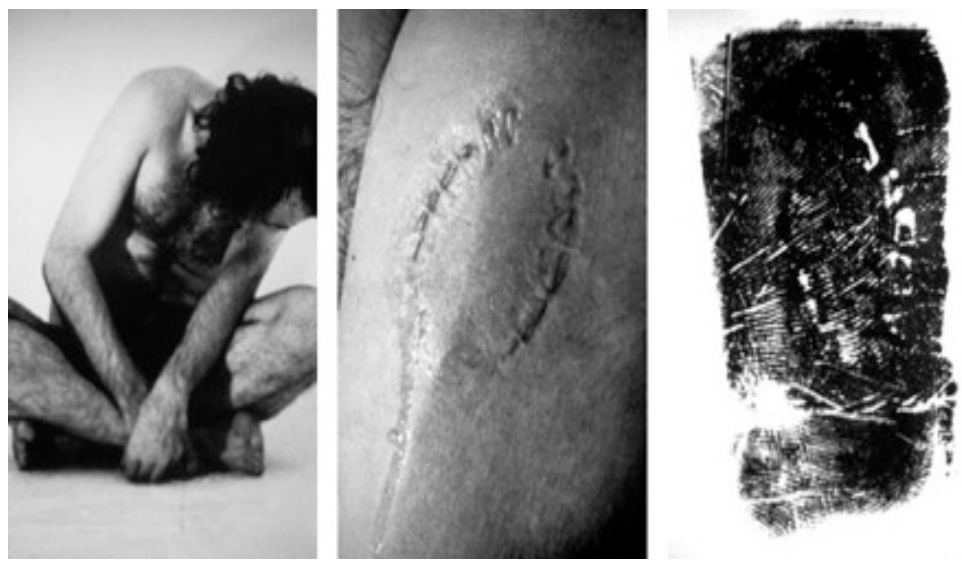

Figura 1. Vito Acconci, Trademarks, 1970 (publicado en la revista Avalanche, 6, 1972)

Como respuesta ante esa ruptura del contrato social, los performers masoquistas de los que habla O'Dell se torturan con una doble necesidad: incidir en lo doloroso de la misma y poner de manifiesto la voluntad de redefinir los términos del contrato por el que el poder se adueña de los cuerpos — apoyándose en Anzieu, O'Dell deja en un segundo plano el horizonte de placer del concepto de masoquismo para centrarse en su dimensión contractual- . La teórica norteamericana afirma que para contextualizar, entender e interpretar el trabajo de Burden, por ejemplo, es necesario considerar su capacidad para cuestionar "la estructura de los contratos", las legalidades vigentes, las confianzas depositadas, los acuerdos tácitos o explícitos. El masoquismo, entendido como una especie de autotortura consciente, implica, por tanto, una reconfiguración de los "contratos" inherentes a toda relación masoquista, los acuerdos entre dos personas que deciden dar y recibir dolor. En cierto sentido, cuando Burden acuerda recibir un tiro en el brazo (Shoot, 1971), recupera parte del control sobre su propio cuerpo en un momento de creciente objetualización del mismo, al tiempo que muestra lo perverso de las relaciones violentas establecidas entre víctima, verdugo y espectador. Tal vez menos conocida es la acción en la que Burden "secuestra" a la presentadora de un canal de televisión que le sometía a una entrevista a propósito de la violencia de sus performances (TV Hijack, 1972). En medio de la emisión, el artista amenaza con degollarla si el realizador no continúa transmitiendo en directo la señal televisiva, en adelante secuestrada. Al cabo de unos instantes, le obligará a destruir la cinta original en la que quedó registrada una señal que sólo podrá ser sustituida por la grabación que el artista ha realizado (Delpeux, 2010, pág. 167). Burden consigue así recuperar el control sobre la imagen mediática de su obra — des-secuestrarla-y los contenidos violentos con que ha sido asociada. El espectador, por su parte, se verá obligado a reflexionar acerca de cuál es su posición ante la violencia, de la que los medios rara vez presentan imágenes que puedan ajustarse a la "realidad" de los hechos, tal y como estaba sucediendo en Vietnam. De hecho, O'Dell afirma que las últimas performance "masoquistas" de Burden y Acconci tuvieron lugar en 1975 y 1973 respectivamente, cuando la guerra de Vietnam tocaba a su fin (1998, pág. 75). 


\section{Performance y nuevos comportamientos}

Si bien es cierto que en el contexto español es difícil encontrar acciones que podamos calificar como masoquistas, performances en las que el artista se torture, se someta a situaciones dolorosas más o menos cruentas - enseguida nos detendremos en tres ejemplos-, sí podemos, en cambio, localizar multitud de trabajos que proponen experiencias táctiles con el fin de superar cierto ocularcentrismo, tal vez como consecuencia directa de esa iconofobia propia del conceptualismo, de su voluntad de ir más allá del puro visualismo y los modos de exhibición del arte elevado. Buen ejemplo de ello serían la serie sobre los subsentidos (1971-1972) de Muntadas (Figura 2), las obras de Fina Miralles (Relaciones del cuerpo humano con elementos naturales en acciones cotidianas, 1974), Eva Lootz (Lavalle, 1974; A-B, 1977) (Figura 3), Antoni Llena (Pintura hecha con sudor y semen, 1967-68), Jordi Benito (Peso y volumen de un cuerpo; Acción y reacción de un cuerpo contra una pared de tierra, 1972-1973; Equivalencia de medidas de distintas partes del cuerpo, 1973), Àngels Ribé (Contar con los dedos, 1977), Esther Ferrer (Íntimo y personal, 1971) o Juan Hidalgo (Hombre, mujer y mano, 1977). Trabajos, todos ellos, que muestran un interés por recuperar el control del cuerpo utilizándolo a su vez como herramienta de conocimiento. Potenciar las capacidades sensoriales del cuerpo - el tacto, y no sólo la vista - en un momento en que éste estaba anulado, atrofiado, en una sociedad patriarcal, ultraconservadora, nacional-católica. Y, al mismo tiempo, reivindicar el cuerpo como propio, asumir su control para arrebatárselo a un Estado dictatorial que, a través de leyes, vacíos legales y diversos mecanismos coercitivos, se había adueñado del cuerpo de sus súbditos.

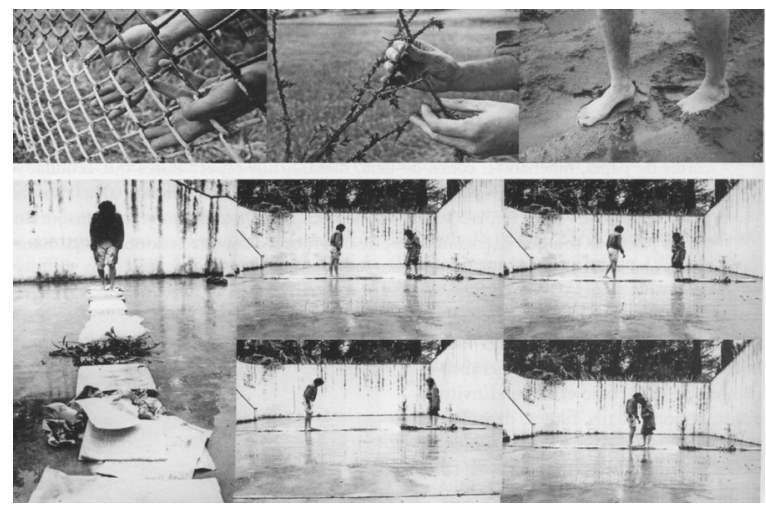

Figura 2. Antoni Muntadas, Acciones subsensoriales, 1971, Vilanova de la Roca, Barcelona, MACBA (Barcelona)

El hecho de que trabajos performativos como los citados hayan sido materializados sobre un soporte fotográfico constituye otro elemento importante en esa revalorización de lo háptico. Para O'Dell, la recepción del arte de acción es eminentemente fotográfica. Lejos de aquellas teorías — las de Peggy Phelan (1993), por ejemploque defienden una posición marginal de la documentación fotográfica con respecto a 
la performance - presencia por encima de representación-, O'Dell va a partir de las fotografías y sus contextos de difusión - revistas, catálogos, archivos, espacios en los que circula la fotografía impresa (O'Dell, 1997) — con el objetivo de fundamentar una teoría háptica de la performance:

"Quien mira la documentación de una performance toca la fotografía tomada por el fotógrafo que toca el disparador de la cámara, del mismo modo que el performer tocó su piel, utilizando su propio cuerpo como instrumento táctil y material para su performance. Esta cadena de experiencias, operando retroactivamente en el tiempo, atrapa al espectador en una complicidad tanto con el fotógrafo como con el performer. Estos vínculos crean los en gran medida tácitos lazos que permiten situar la acción del performer en primer plano. De este modo, la fotografía se convierte en una forma pseudolegal de prueba -término que relaciona fotografía y legalidad - de que un acuerdo ha tenido lugar', (O’Dell, 1998, pág. 14).

Para esta autora, la fotografía se convierte en un elemento sobre el que reconstruir un vínculo/contrato social destruido como consecuencia del uso represivo de los medios y la violencia por parte del poder establecido. El medio fotográfico, reproductible, impreso, contenedor de las performances que se reproducen en revistas y catálogos, deviene una especie de elemento transmisor de estímulos que ya no son sólo visuales. Acordamos que el fotógrafo que pulsa el botón ha estado delante del performer, sentimos su mano sosteniendo la cámara, sentimos la piel del artista que se somete a un castigo corporal. A través de la fotografía estableceríamos, por tanto, un vínculo - simbólico, pero también sensorial - con otro cuerpo que experimenta dolor, frío, la presión de una mordaza o el filo penetrante de una cuchilla.

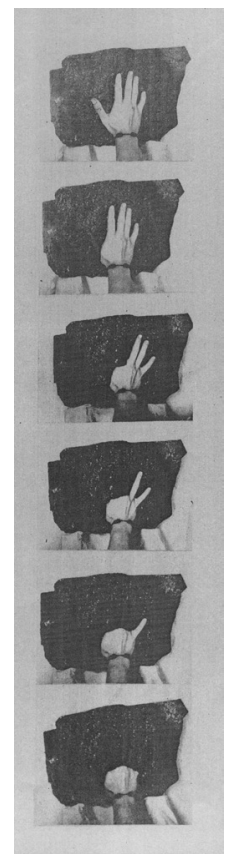

Figura 3. Eva Lootz, Sin título, 1976 (publicado en catálogo editado por la galería Buades, 1976) 
En el contexto español, también podemos localizar algunas acciones más o menos próximas a las estrategias pseudomasoquistas de las que habla O'Dell y que, además, operan en el mismo terreno - el Estado, la institución familiar, la ley- sobre el que la autora americana sitúa las acciones de Acconci, Burden, Pane, etc. En el trabajo de Francesc Torres (Barcelona, 1948), sin ir más lejos, encontramos elementos masoquistas a través de los cuales el artista trata de explorar las relaciones entre los procesos de culturización y la construcción del sujeto. Torres había trabajado en París a finales de los sesenta con el escultor Piotr Kowalski para viajar después a Estados Unidos - a Chicago y Nueva York- . Desde entonces sus proyectos aparecen marcados por una especie de sentimiento de escisión identitaria que le llevará a preguntarse constantemente por la construcción cultural del yo. En An Attempt to Decondition Myself (1973) (Figura 4), el artista bebe alcohol hasta zozobrar, vomitar, perder el conocimiento y caer rendido en una cama (Torres, 1991). En palabras de Bartomeu Marí:

"La necesidad de ejecutar acciones dolorosas o extáticas para adquirir una condición superior (o distinta) del ser es un tema habitual desde el origen de la historia de las civilizaciones y se ha integrado en el sentimiento religioso. Pero Torres no actúa por motivaciones místicas, sino sociales. Su rito apunta ya a la denuncia de las condiciones de una cultura de la hipocresía, que desarrollará en obras posteriores. El cambio de eje en torno al cual gira la obra tenía que hacerse mediante una escenificación protagonizada por el propio artista: escenifica una ruptura y rompe brevemente el prolongado episodio de la búsqueda paracientifica" (Marí, 2008).

Incidiendo en esa misma posición rendida del cuerpo/sujeto, en Almost like Sleeping (Artists Space, Nueva York, enero de 1975) Torres yace dormido en una cama situada en el suelo. Detrás de él, tres proyecciones sobre la pared: a la izquierda, Franco, ya anciano; a la derecha, el abuelo de Torres - izquierdista, represaliado durante la guerra-; en el centro, una película en la que Torres se muerde las uñas hasta destrozarse los dedos. Torres, dormido, muestra así la exposición inconsciente de todo individuo a procesos dolorosos de conformación de la identidad en ámbitos muy diversos: "Franco como condicionador cultural en los planos político y social, (...) mi abuelo como condicionador social en un contexto familiar y cultural" (Torres, 1991, pág. 62). De nuevo, el Estado y la familia, confundidos en un momento en que el dictador aparece como un anciano que adopta una actitud paternalista pero inflexible — en septiembre de ese año llegarían las últimas ejecuciones de la dictadura- . Torres se muestra como un cuerpo débil, frágil, indefenso, convertido en un objeto inerte cuyo inconsciente se configura de una manera necesariamente dolorosa. 


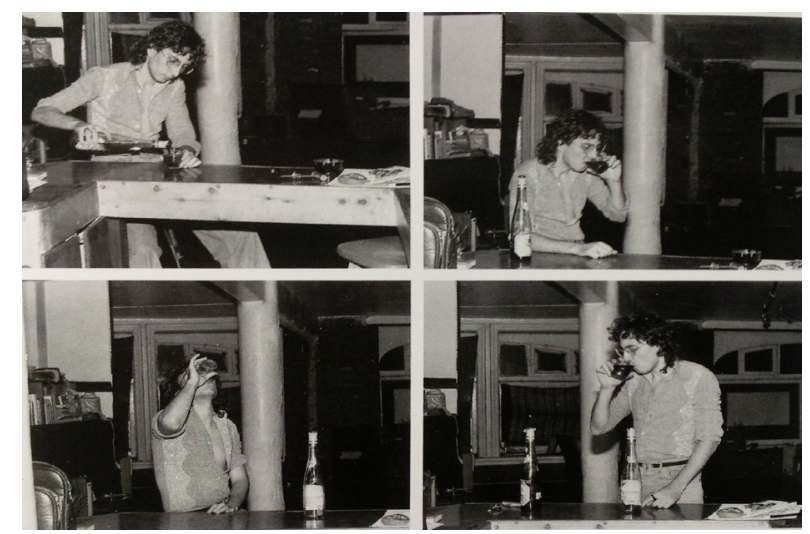

Figura 4. Francesc Torres, An Attempt to Decondition Myself, 1973, MACBA (Barcelona)

Esos mismos procesos fundados en la construcción dolorosa de la identidad subyacen al trabajo de Fina Miralles (Sabadell, 1959). En la conocida acción Standard, desarrollada en la galería G de Barcelona en 1976, Miralles aparece amordazada, sentada en una silla de ruedas, inmóvil y privada de libertad, obligada a mirar una pantalla sobre la que se proyectan diapositivas que recogen escenas estereotipadas de la vida de una mujer, desde que la madre pone un vestido a su hija, hasta que ésta se casa, tiene hijos, etc. Pasajes en los que las mujeres abrazan una serie de convenciones -identidades estándar - sociales que restringen su libertad. En el suelo, frente a la artista, un pequeño monitor emite programas de televisión que reproducen un conjunto de tópicos que reafirman esos mismos roles asociados a una feminidad resitrictiva. Miralles alude a la falta de libertad que sufren las mujeres que, privadas de voz, son sometidas a una educación patriarcal que la familia y los medios de comunicación se encargan de perpetuar. La institución familiar, como el primer ámbito de culturización coercitiva de la personalidad; los medios - la imagen - como la principal herramienta para la construcción de la personalidad sumisa. La artista asume el castigo, se somete a sí misma como estrategia de visibilización que pone sobre la mesa la necesidad de replantear los acuerdos establecidos y naturalizados entre familia, medios de comunicación, el Estado que promulga las leyes y controla el espacio público - recordemos, por ejemplo, que el adulterio no sería despenalizado hasta 1978 - y los individuos — las mujeres, en este caso, como los sujetos más débiles en términos jurídicos - que deben someterse a ellas (Larumbe, 2004, págs. 109-136).

En esta misma línea de trabajo, Enmascarados (1976) (Figura 5) es un conjunto de fotografías en las que el rostro de la actriz Ana Lizarán — que acababa de volver de París para trabajar en el Teatre Lliure - ha sido cubierto con capuchas, plásticos y correas que trasmiten una sensación de asfixia y que nos recuerdan escenas de tortura (Mora Martí, 2004; Parcerisas, 2001). Vemos la máscara en forma de bolsa de plástico con que se asfixia al torturado - bolsa o bañera seca - y la capucha del torturador, del verdugo que oculta su identidad. De algún modo, estas imágenes "ponen en escena" un acto - la tortura - practicado en las comisarías franquistas y del que, necesariamente, no existen documentos gráficos. No tenemos imágenes del trascurso de una tortura, por lo que, como afirma Sophie Delpeux, 
"ante esta ausencia casi total de una iconografia tangible sobre la tortura, laguna condicionada por una inexistencia de documentos o una dificultad para acceder a ellos, los artistas [Burden, Pane, los accionistas vieneses] construirán ni más ni menos que sucedáneos. Dado que la base constitutiva de la tortura moderna es permanecer en su invisibilidad, ellos conjuran esta hipocresía sistémica. Las imágenes de estos artistas, en efecto, pueden ser calificadas como de una iconografía metonímica. Lo que es nombrado en estas fotografias consigue recordar la existencia del horror absoluto de una manera terriblemente eficaz" (Delpeux, 2001, pág. 108).

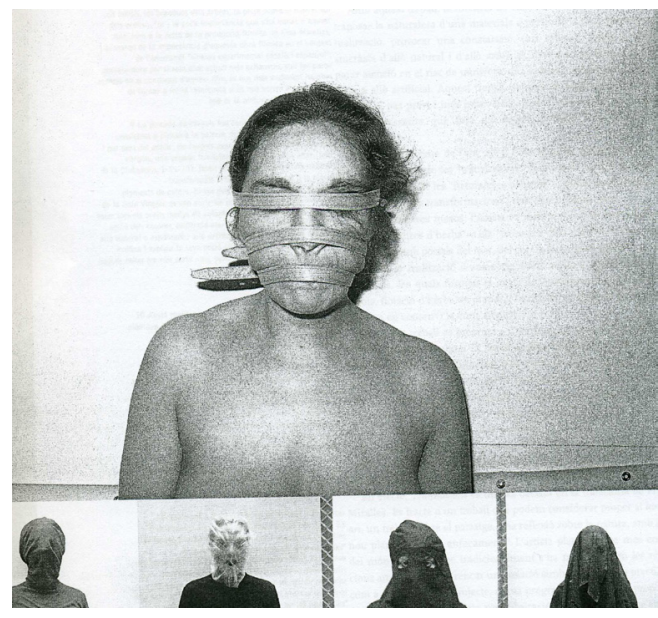

Figura 5. Fina Miralles, Enmascarados, 1976, Museu d’Art de Sabadell (Sabadell)

Recordar el horror absoluto de la tortura y hacer visible lo que el Estado oculta anulando la distancia entre los dos "papeles" del ritual del dolor. En las acciones de Torres y Miralles, torturador y torturado devienen una misma persona. Al exhibir estos trabajos, como performances que pueden ser presenciadas "en directo" o a través de la documentación fotográfica impresa en revistas y catálogos - la mayor parte de las acciones aquí referidas fueron difundidas sobre papel impreso, bien en revistas como Serra d'Or o Nueva Lente, bien en invitaciones y carteles, bien en catálogos de exposiciones_-, desaparece la diferencia entre lo público y lo privado que caracteriza a la tortura. El torturado pierde su intimidad de una manera radical (Savater y González-Fresneda, 1982, págs. 18-19), es obligado a desnudarse, se le agrede sexualmente y se le fuerza a decir lo que el torturador espera que diga. Su voluntad es anulada, su intimidad queda en suspenso. Y, sin embargo, el acto de tortura permanecerá siempre en el ámbito de lo privado, sin salir nunca a la luz pública, salvo por los testimonios de los propios torturados, que al hacerlo se ven obligados a revivir el terror.

También en el trabajo de Jordi Benito (Granollers, 1951-Barcelona, 2008) se produce una inversión de los términos de la tortura. Benito, miembro del Grup de Treball, comienza su trayectoria en una línea próxima al povera para desarrollar después multitud de acciones simples relacionadas con la toma de consciencia del cuerpo, sus 
dimensiones, volumen, resistencia y las posibles interacciones con los elementos de su entorno. Desde finales de los setenta despliega una obra performativa en la que la iconografía cristiana, la sangre y la escenificación del dolor dan como resultado un corpus de imágenes impactantes y provocadoras. Conectando con el trabajo de los accionistas vieneses, Benito construye acciones violentas con una contundente carga ritual.

En la performance Sesiones de trabajo (Fundació Miró, Barcelona, 1979, encuadrada en $V=$ B.P.L.W.B.78.79, 1978-79), Benito contrapone las imágenes de una pareja manteniendo relaciones sexuales ante una reducida audiencia - el amor- y el acto de descuartizar a una vaca viva - la muerte - en un escenario lleno de sangre y vísceras. La acción despertó una enorme polémica por su contenido violento y por la muerte en directo de una animal (Iglesias, 1979). Al hablar de su trabajo, el artista explica:

"Hay dos palabras que me molestan muchísimo. Y me molestarían todavía más si fuesen verdad. Cuando me dicen que hago casquería y cuando me califican de masoquista. Lo primero me molesta porque minusvalora, es peyorativo. En cuanto al masoquismo, a mí no me gusta sufrir. Estoy dispuesto a un pequeño dolor - que suele ser pequeño porque soy miedoso y me cuido de que no resulte peligroso - . Pero acepto que me pique el muslo para dar forma a la idea que tengo. Y la idea que tengo es la imagen de marcar una cruz con hierro incandescente sobre la carne, como se marcan los animales de una ganadería. Artaud decía que él utilizaba la crueldad porque así la gente sentía de una manera más intensa. La sangre la utilizo porque es una sustancia que incita a las sensaciones. Y la violencia puede ser una terapia contra la misma violencia. En la acción se libera crueldad y violencia” (Benito en Queralt, 1983).

Marcar la piel, asumir una dosis de dolor, crueldad asumida como terapia para exorzizar la violencia de una sociedad transicional. Se recupera, como en el caso de Burden, el control sobre el propio cuerpo — control que pierde el torturado en manos de su verdugo, control del cuerpo que el Estado arrebata a sus súbditos- y se transmite una parte de ese dolor mediante la doble experiencia, háptica y óptica, de que nos provee la documentación de la acción. Por supuesto, es imposible trasladar a través de la acción, de la fotografía o de cualquier otro tipo de estrategia simbólica, el dolor que sufre el torturado; o, en el caso de estas performances, la reproducción siempre controlada de una experiencia masoquista. Sin embargo, por pequeña que sea la transmisión táctil de ese dolor, por débil que sea la posibilidad de "sentir el cuerpo", estas imágenes pueden conseguir generar una responsabilidad compartida con respecto a la violencia política. Trasmitir el dolor mediante imágenes contribuiría a generar una consciencia política a través de la conexión de los cuerpos en el dolor, la creación de un cuerpo social consciente de su situación a través de la experiencia del sufrimiento. Paradójicamente, se produciría así la recuperación de los vínculos de confianza que la tortura rompe de manera sistemática.

En aquellas fotografías que configuran un tiempo-espacio para una performance que presenta una acción violenta, más o menos masoquista, el cuerpo aparece como objeto frágil, vulnerable, herido. El espectador, viendo - y tocando - esas imágenes podrá a su vez experimentar, con más o menos intensidad, esa misma vulnerabilidad 
que, en el caso del performer, del artista, no es en absoluto casual. La fragilidad del cuerpo, la vulnerabilidad de la piel, se ponen de manifiesto en un acto consciente y meditado que plantearía una especie de contrato, de relación pseudolegal, entre el documento fotográfico — que puede o no ser tomado por el mismo artista-performer-, el artista y el espectador. Una expansión fenomenológica del dolor autoinflingido a través de la fotografía, que desencadena una identificación entre el espectador que contempla la imagen del dolor y el cuerpo que participa de la escena violenta. Ver y sentir aparecen así como motores del hacer que surge tras experimentar una responsabilidad compartida sobre el dolor. Proceso que, en el mejor de los casos, podría conducir a una toma de consciencia de la situación de los cuerpos en un Estado constante de excepción.

\section{Cuerpos en tránsito}

Nos hemos acercado a acciones "masoquistas" que tuvieron lugar entre los meses anteriores a la muerte del dictador y los años posteriores. Durante la transición, la tortura continuó siendo una práctica habitual por parte de las fuerzas de orden público. El TOP y la Brigada Político-Social continuaron existiendo hasta 1977 — cuando se reconvirtieron en la Audiencia Nacional y la Brigada de Información-y, de hecho, la represión se recrudeció notablemente en varios momentos de ese difícil camino hacia la democracia. Así pues las muertes y torturas impunes no desaparecerán tras el fallecimiento del dictador.

Uno de los trabajos más interesantes sobre esta cuestión es, sin duda, el Homenaje al hombre de la calle (1976-1977) (Figura 6) de Francesc Abad, trabajo documental en el que el artista seleccionó un conjunto de fotografías extraídas de medios de comunicación, montadas sobre papel heliográfico con el encabezamiento de la serie Documentos diseñado por Alberto Corazón — de hecho, la obra de Abad tendría un antecedente inmediato en Piraña, documento sobre la tortura producido por Corazón en 1974-. Imágenes — acompañadas por una grabación de los testimonios de personas torturadas - de las lesiones sufridas por detenidos torturados en dependencias policiales, de asesinados por la misma policía o grupos de extrema derecha y de los últimos fusilados durante el franquismo. Para Abad se trataba de un trabajo de concienciación política, de visibilización de la violencia que podía recaer sobre cualquier ciudadano, sobre cualquier hombre de la calle. Como hemos dicho, no existían documentos de la acción de torturar — de ahí que los performers generen esa iconografía del horror empleando sus propios cuerpos-, pero sí de los efectos de esas torturas sobre cuerpos de individuos con nombres y apellidos. Detenerse en las consecuencias de la acción incide de nuevo en la imposibilidad de acceder a las imágenes de la tortura. Al mismo tiempo, Abad saca a las víctimas del anonimato, les devuelve su identidad sirviéndose de fotografías y documentos que participan de una estética de archivo, herramienta que la policía empleaba con el fin de controlar a los disidentes. Sustraer al archivo su capacidad de identificar y nombrar para desvelar la violencia estructural que el Estado pretendía ocultar; dotar al archivo de una nueva utilidad como contenedor de la memoria de las víctimas. 


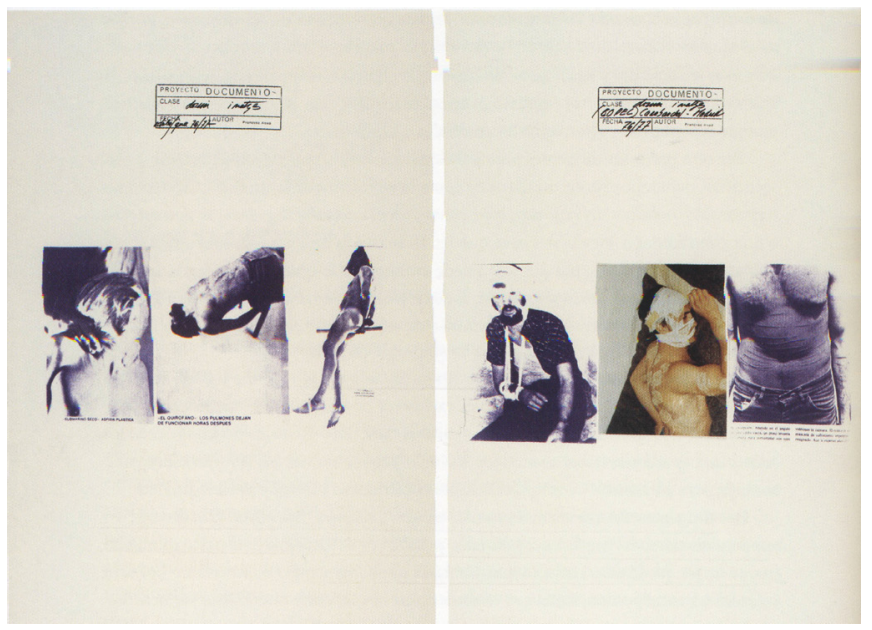

Figuras 6. Francesc Abad, Homenaje al hombre de la calle, 1976-77, MNCARS (Madrid)

Hay que tener en cuenta que los mecanismos coercitivos del Estado franquista, la represión de los cuerpos por parte de instituciones como la Brigada Social, el TOP, etc., sólo tenían sentido en una búsqueda constante y obsesiva del enemigo. Un enemigo polimorfo, carente de un perfil definido — desde los monárquicos liberales a los comunistas prosoviéticos-, que debía ser construido como un todo perverso en términos performativos - mediante la repetición de una serie de consignas y estereotipos: el rojo, el separatista, el desafecto, el terrorista-, e identificado y reprimido con eficacia. Para ello resultaba imprescindible la información obtenida mediante la tortura, convenientemente archivada y procesada. En el trabajo de Abad, ese enemigo abstracto aparece como un individuo identificado, como una víctima de la brutalidad más abyecta que, conocida por todos, rara vez era objeto de tratamiento en los medios de comunicación debido al férreo control estatal sobre los mismos. Visibilizar un problema conocido al que se le da la espalda, puede parecer una estrategia un tanto ingenua. Y, sin embargo, en ocasiones ha demostrado ser muy eficaz a la hora de generar una conciencia crítica en una ciudadanía desinformada.

A propósito del uso de la tortura durante el franquismo, Mercè Garcia Aran, catedrática de Derecho Penal de la Universidad Autónoma de Barcelona, explica:

"Un estado autoritario se asienta por definición en la eliminación de la disidencia política. Para ello, no basta con descubrir y eliminar al disidente, sino que es necesario, además, establecer el principio de que el Estado dispone de los derechos de sus súbditos. Así, el abuso y la tortura policial en una dictadura no son explicables como simples desviaciones patológicas de algunos funcionarios que creen servir a altos intereses, sino que forman parte de una estrategia de dominación que reduce a las víctimas a la condición de objetos a disposición de los aparatos de poder. Estrategia de dominación sobre la víctima inmediata, para que delate a los otros, utilizándola como instrumento de investigación útil en la espiral represiva y, también, estrategia de dominación social, en la medida en que el maltrato, la vejación, las lesiones y, eventualmente, la muerte, son consagrados como métodos utilizables en la protección del modelo político. Y como métodos necesarios, deben ser impunes" (Garcia Aran, 2007, pág. 52). 
No es casual que en el Código Penal vigente durante la dictadura la tortura no aparezca tipificada como delito. En la legislación española, no aparecerá como tal hasta 1978. Sin embargo, cualquier daño, lesión o trato vejatorio, producido en ámbitos públicos o privados - también en la comisaría - eran considerados actos delictivos durante el franquismo. Las estructuras del complejo aparato de represión dificultan la atribución de responsabilidades con respecto a las torturas. Las lesiones producidas durante un interrogatorio eran "claramente punibles, pero también claramente impunes" (Garcia Aran, 2007, pág. 53). Posteriormente el afianzamiento de esa impunidad con los pactos transicionales que se concretan en la Ley de Amnistía de octubre de 1977 pueden ayudarnos a comprender sobre qué se funda nuestra democracia nuestra cultura democrática y nuestra cultura en democracia-. Dicha ley amnistió a los condenados por delitos políticos durante el franquismo, pero también a las "autoridades, funcionarios y agentes del orden público por los delitos que pudieran haber cometido en la investigación y persecución de la disidencia”. De alguna manera la ley admite que los cuerpos represores habían cometido delitos punibles durante el franquismo y ya en democracia. Los represaliados, muchos de ellos inocentes de los delitos de los que se les acusaba durante la dictadura, eran también inocentes en una democracia por la que tanto habían luchado. Los políticos franquistas, reconvertidos en demócratas convencidos, admitían sus posibles responsabilidades, eso sí, sobre los delitos cometidos por sus subordinados. Se aseguraban así de no tener que responsabilizarse, de que sus propios delitos quedaran impunes (Garcia Aran, 2007, pág. 57). La tortura aparece así como la desviación de unos funcionarios que se exceden en el cumplimiento de sus obligaciones, y no como el mecanismo de supervivencia de un Régimen dictatorial que reprimía con dureza el ejercicio de las libertades.

Posteriormente la tortura ha seguido y sigue siendo una triste realidad en nuestra democracia. Existen un sinfín de denuncias avaladas por Amnistía Internacional y otros organismos que luchan por el respeto de los derechos humanos, así como numerosas sentencias condenatorias. Durante los ochenta, y pese a que muchos de los artistas de los que hemos hablado continuaron trabajando en una línea próxima a los nuevos comportamientos, es difícil encontrar trabajos que conecten de manera más o menos consciente el cuerpo social, absolutamente desactivada, y el de unos artistas definitivamente despolitizados. Los nuevos comportamientos, como la violencia política, tuvieron cierta continuidad durante los años ochenta, carentes, eso sí, de la atención mediática y el apoyo institucional que acaparan otras prácticas de orientación más hedonista. Se iniciaba entonces un doloroso proceso de desactivación de la cultura en un cuerpo social con enormes carencias en lo que a cultura democrática se refiere.

Trabajo desarrollado en el marco del proyecto Plataforma de investigación y desarrollo: artes visuales y puesta en escena en la era digital (Junta de Castilla y León, Universidad de Salamanca). Investigador principal: Dr. D. Javier Panera Cuevas (USAL). Referencia: SA024A10-1. 


\section{Referencias}

Albarrán, J. (2010). Estéticas de la resistencia en el último franquismo. Entre la in vestigación formal y la consolidación del movimiento asociativo. Artigrama, 25.

Águila, J. J. del (2001). El TOP. La represión de la libertad (1963-1977). Barcelona: Planeta.

Batista, A. (1995). La Brigada Social. Barcelona: Empúries.

Delpeux, S. (2001). Document d'époques. Fiction et torture. Art press, hors série.

Delpeux, S. (2010). Le cops-caméra. Le performer et son image. París: Textuel.

Gallardo, J. J. (2003). Tortura y transición democrática. El caso Téllez. Madrid: Carena.

Gallardo, J. J. (2006). La tortura bajo el franquismo. En, Contra Franco. Testimonios y reflexiones. Madrid: Vosa.

Garcia Aran, M. (2007). Impunidad. La comisaría. En, En transición. Barcelona: CCCB.

Gómez Roda, A. (2005). La tortura en España bajo el franquismo. Testimonio de torturas durante la dictadura y la transición a la democracia. Pasajes de pensamien to contemporáneo, 17.

Iglésias del Marquet, J. (1979). Entre el amor y la muerte, un ejemplo del arte de acción. Diario de Barcelona, 7 de julio.

Larumbe, $\mathrm{M}^{\mathrm{a}}$. A. (2004). Las que dijeron no. Palabra y acción del feminismo en la Transición. Zaragoza: Prensas Universitarias de Zaragoza.

Marí, B. (2008). Francesc Torres y el museo. En, Da capo. Francesc Torres. Barcelona, MACBA.

Moreno, F. (1999). La represión en la posguerra. En Juliá S. (Coord.), Víctimas de la Guerra Civil. Madrid: Temas de Hoy.

Mora Martí, L. (2004). Desplazamientos y recorridos a través del Land Art en Fina Miralles y Àngels Ribé en la década de los setenta. Valencia: Universidad Politécnica de Valencia.

Núñez, M. (2005). Arte y política en la España del desarrollismo. Madrid: CSIC.

O'Dell, K. (1997). Displacing the Haptic: Performance Art, Photographic Document, and the 1970's. Performance Research (2)1.

O'Dell, K. (1998). Contract with the Skin. Masochism, Performance Art and the 1970s. Minneapolis: University of Minnesota.

Parcerisas, P. (2001). De la naturalesa a la naturalesa. En, Fina Miralles. De les idees a la vida. Sabadell: Museu d'art de Sabadell.

Peters, E. (1987). La tortura. Madrid: Alianza.

Phelan, P. (1993). Unmarked: The Politics of Performance. Nueva York: Routledge.

Queralt, R. (1983). Crida, art, crida y lamenta't, perquè ja ningú et desitja, ai de tu. En, Jordi Benito. Assaigs per a L'Opera Europa. Barcelona: Fundació Caixa de Pensions.

Savater, F., y Martínez Fresneda, G. (1982). Teoría y presencia de la tortura en España. Barcelona: Anagrama.

Sontag, S. (1981). Sobre la fotografía. Barcelona: Edhasa. 
Torres, F. (1991). An Attempt to Deconditioning Myself. En Hanhardt, J. (dir.), Francesc Torres. La cabeza del dragón. Madrid: MNCARS.

Vidal i Marsans, S. (2006). Los tribunales de justicia durante el franquismo: crónica de una arbitrariedad olvidada. En, Contra Franco. Testimonios y reflexiones. Madrid: Vosa. 